\title{
Marc Fellenz
}

\section{A Trace of Kinship: The Place of Animals in Environmental Aesthetics}

Introduction. The pressing reality of looming environmental degradation has made the revaluation of long-held attitudes toward the natural world a practical necessity. Important contributions have been made to this moment of reckoning by philosophers of environmental ethics, whose work moves the conversation beyond a preoccupation with human self-interest to include analyses of the moral standing of nonhuman elements of nature and the appropriate conceptual framework for including the natural environment within the field of moral concern. Yet not all the recent philosophical reflections on nature have worked within the normative categories of natural rights and moral obligations. The past several decades also have seen increased attention to the special issues raised by the aesthetic appreciation of natural environments, moving philosophical aesthetics beyond its traditional focus on the philosophy of art. ${ }^{1}$ At the same time, thinkers in the continental tradition have highlighted the philosophical significance of our experience of nature by extending the phenomenology of place to our encounters with the nonhuman world. ${ }^{2}$ These philosophical efforts urge that experience in nature should inform the emergent rethinking of the human/nature relationship, and that aesthetics should hold a place along side political, moral, and utilitarian considerations in the formulation of environmental principles.

That philosophers now should be attending to the aesthetics of our experience of nature is perhaps not surprising, given the growing attention to environmental themes in art, literature, and popular culture. More significantly, just as the ethics, epistemology, and ontology of the post-Darwinian era have been challenged by the need to reassess traditional anthropocentric positions, aesthetic theory also must explore a broader terrain beyond our aesthetic responses to human art and artifacts. Moreover, this work carries great practical significance. As history shows, moral and political transformations rarely are accomplished through theory and argument alone, but require an affective ground that is prepared to nurture change; thus, attention to and encouragement of aesthetic encounters with the natural world may have an important role to play in the theoretical efforts of environmental ethicists bearing fruit in policy and practice. 
However, efforts at analyzing the aesthetic appreciation of nature are complicated by the very problem that prompts this renewed analysis: the need to rethink the human/nature distinction. The categories "human" and "nature" have been conceived and constructed in multiple ways that in turn feed disparate means of conceptualizing and approaching the nonhuman world. The subsequent ambiguity concerning both the subject and object of the aesthetic appreciation of nature has resulted in many competing models for understanding the aesthetics of natural environments, and a consensus has yet to emerge on many fundamental questions: What, if anything, distinguishes the aesthetic appreciation of nature from that of human artifacts and environments? What, if anything, must the human observer bring to an encounter with nature in order for any subsequent appreciation to be properly aesthetic? What, if any, meaning is to be derived from those occasions when the natural world functions as a source of aesthetic satisfaction?

In this article, I do not attempt to address the full range of problems these questions raise and the literature devoted to them. Rather, I argue only that some insight into these matters may be gained by attending to the underappreciated place of nonhuman animals in environmental aesthetics. The experience of natural environments as habitats - dwelling places for animate beings to which humans are related in complex ways is fundamental to dimensions of nature aesthetics that are prominent in our contemporary circumstance. Experiencing wild animals and the environments they inhabit creates the opportunity for aesthetically powerful recollections of the historical and pre-historical ties to the nonhuman world surrounding our domesticated enclaves. Today, given how remotely many humans live from that world and the prospect that the distance will only increase in the future, these recollections will permeate many aesthetic encounters with nature and inform the value of those experiences.

The inspiration for my approach comes from several sources, the first being the simple desire to make sense of my own aesthetic appreciation of nature, in which encounters with animals and their habitats have held a central place; no doubt, there are points in my analysis where philosophical rigor is eclipsed by a more personal search for a language adequate to my experiences. Nonetheless, a second, philosophical motive is at work here as well: I have argued elsewhere that, despite the valuable work done by environmental ethicists and animal rights advocates, our traditional ethical models have proven inadequate for articulating the normative value of the animal's world, and that a complete axiology of animals and the natural environment must transcend 
concern for the logical consistency of our moral reasoning to include analysis and experience more akin to aesthetic appreciation. ${ }^{3}$ This essay is an effort at developing the point in the converse direction by arguing that a complete understanding of natural environmental aesthetics requires some reflection on encounters with wild animals.

Deconstructing Plotinus. The third source for this paper is the most unlikely one: the aesthetic theory of Plotinus, the third-century founder of Neoplatonism. In his treatise "On Beauty" in the first of the Enneads, Plotinus reflects on the nature of physical beauty in this way:

So let us ... state what the primary beauty in bodies really is. It is something which we become aware of even at the first glance; the soul speaks of it as if it understood it, recognizes and welcomes it and as it were adapts itself to it. But when it encounters the ugly it shrinks back and rejects it and turns away from it and is out of tune and alienated from it. Our explanation is that the soul, since it is by nature what it is and is related to the higher kind of reality in the realm of being, when it sees something akin to it or a trace of its kindred reality, is delighted and thrilled and returns to itself and remembers itself and its own possessions. (237)

What are we to make of this intriguing text? Ostensibly, Plotinus's meaning can only be discerned in a metaphysical context, namely, the dualism of form and matter central to Neoplatonic ontology. On this standard reading, the fundamental point of the text is that the elevation of material reality to a state that might properly be described as "beautiful" can only be explained by matter's submission to and participation in spiritual form. Only with this dualism in mind can one also appreciate Plotinus's subsequent argument that the true beauty of a human being rests with the intelligible soul and its natural function of giving form to the material body. ${ }^{4}$ Although Plotinus assigns a somewhat more positive value to the appreciation of material beauty than did earlier Platonic thought, it is only by invoking the triumph of form over matter that Plotinus can make sense of the human soul recognizing and welcoming aesthetically beautiful material objects. Consistent with classical models, this reading shows the metaphysics and aesthetics of Plotinus's system to be mutually reinforcing.

Indeed, Plotinus's philosophy is typical of the ontological and evaluative dualism that has underlain the West's traditional elevation of the cultural, the spiritual, and the intelligible at the expense of the natural, the physical, and the animal, and so his text

Humanimalia: a journal of human/animal interface studies

Volume 2, Number 2 (Spring 2011) 
would seem to be an unlikely starting point for a post-humanistic discussion of nature aesthetics. However, there is another dimension to this text that deserves attention. If we set aside Plotinus's metaphysical explanation of the soul's aesthetic responses, we find that Plotinus is also offering a rich phenomenological description of the aesthetic experience itself, of what the soul "sees" and "speaks" in the presence of material beauty. By bracketing the categories of ontological dualism, a phenomenological reading discloses a text that is separable from Plotinus's metaphysical project; indeed, the naturalistic overtones of Plotinus's language invites interpretations of the text quite at odds with his presumed intention. Moreover, this deconstruction is not warranted merely by the play of words, for the resulting text illuminates several significant features of aesthetic experience that modern aesthetic theories have not emphasized. Furthermore, although Plotinus's account is indifferent to the distinction between art and nature, I argue that these features are especially evident in certain types of aesthetic encounters with natural environments. Thus, reflection on this text will prove valuable for thinking through some problems of environmental aesthetics.

Aesthetic Kinship. Like many later accounts, Plotinus's description locates aesthetic experience in a relational context. The aesthetic encounter is experienced as a welcoming accommodation in which the subject readily adapts to [sunarmóttetai, fits together with] the object. Thus, it is only by standing in a certain relationship to the object that the soul will have the experience of beauty. However, unlike Kantian theories that define the aesthetic relation in terms of disinterestedness or distance, Plotinus uses the very different language of kinship. Plotinus's aesthetic observer experiences the beautiful aesthetic object as akin [suggenès], of the same family, whereas the ugly is present as alienated [allotrioumènê]. Neither identical to the subject nor "out of tune" with her, the aesthetic object is a relative - other, yet related. Furthermore, the language of kinship invites a deeper challenge to modern aesthetic models - consistent with the post-modern criticism of such thinkers as Dewey and Heidegger - by locating the aesthetic outside the subject/object dualism that defines the arena of modern epistemology. Indeed, it suggests that in aesthetic experience the subject and object are not entirely separate, for such experience is grounded on the shared origin of observer and observed, their natural connectedness. In Plotinus's description, the experience of beauty is the aesthetic awareness of this relatedness.

The suggestion that a sense of kinship is a defining feature of the aesthetic is provocative, but how broadly may we apply Plotinus's description? Even if we leave 
behind the Platonic metaphysics with which he supports it, is what we may call the "kinship model" appropriate to the variety of occasions that are generally recognized as aesthetically evocative? Although my focus here is the aesthetics of nature, Plotinus's language of kinship seems vindicated to the extent that it allows us to articulate certain fundamental aspects of the aesthetics of art. For example, consider the vaunted - if arguable - ability of great art to transcend historical and cultural barriers and form bonds between unacquainted artists and audiences, revealing "kinship" with sisters and brothers of distant places and times that might otherwise remain unacknowledged. At the extreme, today we may find ourselves strangely fascinated by ancient artifacts and the odd sense of connection their creators' aesthetic choices provoke in us; it is also apparent that contemporaries and compatriots may experience a heightened awareness of relatedness through shared artistic encounters. Plotinus's language of "kinship" resonates with later accounts of these phenomena - such as the Kantian description of the peculiar "subjective universality" demanded by the judgments of taste, or Tolstoy's discussion of the "infectious" nature of genuine art that destroys the spiritual gaps among disparate individuals - and thus is consistent with a history that recognizes a sense of relatedness as a component of the experience of art.

More to the point of Plotinus's description, however, this sense of relatedness may also extend from the audience to the artwork. Just as artists commonly refer to putting something of themselves in their work, the non-artist who is moved by an artwork also may feel peculiarly connected to it. The appreciator of art is broadened and enriched by feeling related to something coming from without ("That speaks to me"), experiencing the object itself as "akin" - something other that is nonetheless curiously related - if only metaphorically. In part, this may reflect a general human tendency to anthropomorphize artifacts and imbue inanimate objects with subjectivity they do not in fact possess. However, whatever the ultimate psychological foundation of such experiences, Plotinus's account - that in beauty we are drawn to an awareness of a peculiar kinship with what we would otherwise think of as unrelated - aptly describes some of the complexity of aesthetic experience.

But what of our aesthetic experience of natural environments? If the experience of beauty is indeed a felt sense of kinship, then it is plausible that the "beauty" we find in nature - an admittedly vague notion, which has been conceptualized in innumerable ways - may be informed with a sense of kinship that is evoked by a wild encounter. Indeed, the language of kinship offers interesting possibilities for articulating our aesthetic reactions to nature, for our connections to the natural world are especially complex and multilayered, covering degrees of relatedness that are both metaphorical

Humanimalia: a journal of human/animal interface studies

Volume 2, Number 2 (Spring 2011) 
and literal. The biological sciences provide a variety of conceptual models - from the ecosystemic to the genetic - for thinking about the relationships between humans and the larger biosphere; certain religious doctrines from various traditions also suggest that humans have essential ties with the natural world. The aesthetic encounter with nature may be experienced as an alternative, affectively potent way of confronting these alleged connections. No doubt the formal aesthetic properties of landscape, scenic vistas, and discrete natural objects account for some of the aesthetic value of the natural world; grace, balance, symmetry, and variety can carry aesthetic power regardless of the objects that exhibit them. However, the language of kinship expresses more than the appeal of these properties, allowing us to attend to the aesthetic impact of our complex relatedness to the nonhuman world, and thereby illuminating aspects of nature aesthetics that otherwise might go unnoticed. As I argue in the subsequent, the kinship model also provides a fruitful framework for analyzing the variety and historicism of the aesthetic appreciation of nature.

The Place of Animals. The myths and liturgies of the prescientific age are filled with images that express a sense of human kinship to inanimate elements of the natural world. Still today, some will use the language of kinship to describe their aesthetic responses to natural geography, landscape, and flora - to report feeling strangely connected to these nonconscious components of nature. However, the image of kinship invites us to give special attention to the relationships between humans and other animals, where literal biological connections, spanning a wide range of distance and closeness, obtain. These connections defy simplistic interpretations, and cannot be understood without appreciating the ambiguous web of similarities and differences between humans and the rest of the animal world. Yet, awareness that humans hold some type kinship with animals has inspired an array of cultural products, from the ancient religious belief in trans-species reincarnation to the recent technological accomplishment of trans-species organ transplants. The efforts of generations of philosophers, psychologists, anthropologists, and biologists have eroded every oncefirm division between human and animal realities, revealing continuity and kinship at the moral, epistemological, and even cultural levels. In considering the ethical significance of human/animal interactions in her Animals and Why They Matter, philosopher Mary Midgley offers up the image of a "mixed community" to describe the complex of overlapping relationships that humans have developed with the socializable animals they have domesticated; her point is to argue that as rightful members of this community, domesticated animals are entitled to some direct moral standing. With 
justification we may extend her point with the image of an "extended family": humans and animals, literal kin through their ancient genetic ties, viewed as co-evolving through the history of domesticated civilization and, in the process, forming multiple bonds of social "kinship."

Plotinus's description of the experience of beauty leads to the prediction that these bonds will be aesthetically potent material, a prediction that is confirmed even if we limit ourselves to the artworld. Human-animal interrelationships emerge in widely varied artistic manifestations, from the recurrent literary and dramatic themes of human-to-animal metamorphosis and humans living among animals, to bodymodification artists who surgically alter themselves to assume animal forms. Mark Dion, Xu Bing, Wim Delvoye, Bansky, and many other contemporary artists have made compelling use of the powerful aesthetic presence of live animals, and their work consciously exploits more than the formal aesthetic properties of animal bodies. As Steve Baker has discovered through this type of art, the ambiguous territory occupied by animals - related yet other - renders their very existence a medium with unique artistic possibilities. $^{5}$

Of fundamental importance to environmental aesthetics, this curious aesthetic power of animals is also at work in certain encounters with nature. Consider that the aesthetic presence of what may appear to be an uninhabited, "azoic" environment is fundamentally different from that of an encounter with wildlife. A powerful shift occurs when animals present themselves in a natural setting: the seal that emerges on a harsh shoreline, the hawk that pierces the otherwise empty sky, the frog that disturbs the still pond. With such appearances distanced scenery is transformed into encompassing habitat, and the formal, mostly visual, aesthetic properties of the environment become enriched, if not supplanted, by other data provided by smell, sound, and kinesthetic sensations. In the presence of wild animals, the aesthetic response to a natural environment can undergo a decided shift away from the passive observation of appealing vistas to something more intense and engaging. The kinship model offers an effective way of accounting for such shifts. In these moments, it comes to be felt (not simply thought, but felt): A living, embodied being, in ways akin to myself, is at home here.

As Midgley's analysis suggests, the sense of human/animal kinship informs several morally significant relationships with domesticated animals. Yet how much more provocative is the image of kinship when applied to wild animals living in natural environments. Such creatures are living, embodied, mortal creatures like ourselves, yet

Humanimalia: a journal of human/animal interface studies

Volume 2, Number 2 (Spring 2011) 
they inhabit neither cage nor barnyard nor house, but rather places at the margins of civilization and beyond. They are clearly related to us, but also starkly other. Their place in the world is very different from ours, and consequently any sense of relatedness we feel to such beings may be more challenging than the kinship we can feel toward our fellow humans, artifacts or pets. Trying to accommodate that challenge in moral terms has proved daunting for the fields of environmental ethics and wildlife management. However, as a description of aesthetic experience, the kinship model allows us to articulate the intensity of certain encounters with wild animals in natural environments, and prepares the ground for appreciating the significance of such moments.

Kinship and the Problems of Environmental Aesthetics. Plotinus's kinship model of aesthetic experience provides a fitting vocabulary to describe certain types of aesthetic encounters with nature, and draws our attention to the special place that our experience of animals may have in the aesthetic appreciation of natural environments. The value of this model is born out by a brief look at the fruitful pathways it provides for approaching several philosophical problems in environmental aesthetics.

Art and Nature. As noted above, a central question for environmental aesthetics is whether any features of our aesthetic response to natural environments distinguish it from the aesthetic appreciation of art and artifacts. Some standard responses are: (1) to stipulate that aesthetics simply is art appreciation, and that therefore whatever satisfactions the experience of nature offers must be analyzed in non-aesthetic categories (conceptual understanding, spiritual stimulation, pragmatic goods, etc.); (2) to recognize that nature does afford genuinely aesthetic experience, but only to the extent that it presents us with formal aesthetic properties (symmetry, contrast, diversity, etc.) that are also at work in aesthetically effective art and artifacts; (3) to recognize that both art and nature offer aesthetic experience, but that they do so, at least in part, on separate bases. Variations of this third possibility are found amongst the recent attempts to think through an aesthetics of nature while recognizing the unique reality of environments as distinct from discrete objects. The kinship model offers an additional option: a sense of relatedness may inform all manner of aesthetic experience, but the nature of the relation, and thus the tone and intensity of the experience, will vary depending on whether the occasion is artifactual or natural (with further room for variation within each of those categories). A buck painted by Landseer and a pig tattooed by Delvoye may both evoke aesthetic reactions that exploit human/animal 
kinship, but with very different intentions and to very different effects. Different still will be the experience of an aesthetic immersion in a natural environment, mediated through an encounter with wildlife; to be drawn into a sense of connection with the natural world is a unique but still aesthetically charged experience, analogous to, yet phenomenologically distinct from, that of being drawn into the artworld through the mediation of an artwork. Despite important differences amongst these aesthetic experiences, the flexible notion of kinship provides a coherent framework for discussing them all.

Additionally, the kinship model helps to explain an important difference between nature and art that was recognized by Kant: that the aesthetic appreciation of nature cannot be entirely "disinterested," for unlike the satisfaction offered by aesthetically powerful artwork, the beauty found in natural objects is contingent upon their genuine material existence. If our aesthetic appreciation of nature were simply a response to the formal properties of natural objects, it would be difficult to explain the phenomenological difference between the aesthetic impact of natural objects and that of convincing fakes (Kant's own explanation - involving awareness of our moral superiority over nature - is notoriously strained). We may still enjoy the tune when we discover that what we thought was a birdsong is in fact an accomplished imitation; the forms and colors in a bouquet may be just as pleasing whether they are embodied in silk or natural petals. Yet, when we are tricked into accepting an artifact as a natural object and the error is revealed, an evident shift in the aesthetic experience occurs something distinct from the analogous situation of, say, being duped by the forgery of an artwork. The kinship model explains this shift through the different senses of kinship that may be felt in the cases of aesthetically moving artifacts and natural objects. It is quite possible to feel a sense of relatedness to an artifact that imitates a natural object; as was noted above, kinship may attend the aesthetic reaction to a work of art, which may include a photorealistic landscape painting or a silk flower. However, to feel akin to something not of human origin will be a more interesting and challenging experience, and this is the distinctive feature of certain aesthetic encounters with nature - most powerfully in the presence of living animals. Animals are present as realized possibilities of life in the natural world; their aesthetic appeal is not exhausted by their graceful, symmetrical natural forms but also includes the link they provide to those embodied possibilities.

The Variety and Context of Aesthetic Experience. Because it provides a coherent framework for articulating the aesthetic satisfactions to be found in a range of artistic and natural encounters, the kinship model is able to match one of the strengths of the

Humanimalia: a journal of human/animal interface studies

Volume 2, Number 2 (Spring 2011) 
"distance model" by allowing us to account for the variety of aesthetic experience both in terms of the different degrees of aesthetic satisfaction typically found in various types of objects as well as the subjective differences among the experiences of individual observers. Specific to nature aesthetics, some may respond to verdant landscape that offers homes to large, culturally significant mammals, while others may respond to termite mounds or the shed skins of snakes. There are degrees of kinship to be found in each of these natural presences, and particular individuals and cultures will - for historically constructed reasons - be more attuned to some than others. Moreover, the complicated kinship between humans and the broad range of animal life provides a tool for contextualizing these different aesthetic experiences. In the postDarwinian world, the relatedness of humans and other animals is generally acknowledged, but has proven ambiguous in its implications for the human selfconcept. Simultaneous with this period of crisis, the aesthetic impact of nature has taken on an urgency - evidenced by the recent philosophical attention it has received - that is not apparent in other eras. In those cultural circumstances in which humans understand themselves as either fully immersed in the animal's world or completely separate from it, the aesthetic presence of nature will be very different, if not missing entirely. I will not pursue it in detail here, but analysis may reveal interesting correlations between the significance of the natural world as an aesthetic object and the understanding of the human/animal border. For example, amongst the ancient Greeks and throughout much of Christendom, the human/animal boundary was absolute, and at the same time "nature" was not generally viewed as something beautiful; conversely, where human/animal kinship is culturally institutionalized, the natural world has important spiritual, psychological and economic importance, but is not typically viewed as an object of aesthetic engagement. For many of us today, the connections between humans and animals are more problematic and ambiguous, and perhaps this complexity creates the climate for the type of aesthetic appreciation of nature that has provoked the contemporary discussion.

Subjectivity and Objectivity. Recognizing that our experienced kinship with wild animals is an important element in the aesthetic appreciation of nature also sheds some light on the complex relationship between the subjective and the objective in this type of aesthetic experience. By definition, the appreciation of a natural environment requires the acknowledgment of a larger, extra-human context in which the human observer is situated. Reflected in the thought of deep ecology, many naturalists have decried the anthropocentric efforts to reduce the value - aesthetic or otherwise - of the 
nonhuman world to what may be expressed in the familiar categories of human culture, efforts that undermine the objective power of nonhuman nature to act upon us. With this in mind, those accounts of nature aesthetics that are modeled on the aesthetic appreciation of art and reduce the aesthetic impact of natural environments to the effects of their formal properties might be viewed as tantamount to domesticating the encounter with nature, an attempt to tame our experiences of the nonhuman world by confining them within the walls of human subjectivity and our pre-established categories of meaning.

On the other hand, it must be granted that we can only have aesthetic appreciation of what is assimilable to our human sensibility, of what, as Plotinus puts it, we can "fit together with," and this is inevitably shaped by the all too human operations of history, technology and political power. As Allen Carlson argues, some degree of "artifactualization" - the assimilation of nature to where we are - may be necessary in order for aesthetic appreciation to be possible. ${ }^{6}$ Yet this does not mean that all aesthetic encounters with nature are purely the result of human subjectivity being splashed across the canvas of nature (even if many such encounters may amount to just that). Another possibility presents itself in the being of a nonhuman animal, which embodies its own perspective on the natural world. Of course, the lives of animals are as vulnerable as the rest of nature to being obscured by the projected meanings and myths of human culture. But, through the recognition of our kinship, our shared vitality and mortality, the animal may also serve as an empathetic object that draws us outside our usual selves. The animal thus embodies a human-scale focal point around which the aesthetic experience of nature may be framed, and plays a uniquely valuable role in maintaining balance between the subjective and objective poles of the experience. ${ }^{7}$

Aesthetic Traces. While this survey is cursory, it makes a preliminary case for the power of the kinship model of aesthetic experience and its potential value for environmental aesthetics. Yet even if this is granted, a potentially serious limitation on its application to the aesthetic appreciation of nature needs to be addressed. While generations of environmental thinkers have argued that humanity must nurture its ties to the natural world, their advice runs against a long and deep current in Western thinking which has held that the nature of man demands transcendence of the rest of nature. Thus, it may not be obvious to modern observers that the beauty they find in natural encounters is indeed the experience of kinship, rather than a distanced appreciation of the formal aesthetic properties of natural objects and vistas or - the more problematic Kantian position - an indirect awareness of our superiority over nature. Plotinus, agreeing with later empiricist aestheticians, indicates that there is

Humanimalia: a journal of human/animal interface studies

Volume 2, Number 2 (Spring 2011) 
something immediate in the experience of the beautiful, for it is recognized "at the first glance." How then will the kinship model account for the presence of nature as an aesthetic source when there are many for whom any "kinship" to the natural world may not be apparent at the first - or even second or third - glance?

A possible answer to this difficulty is suggested by the phenomenological reading of Plotinus's text. Although he states that beauty will be apparent at first glance, Plotinus writes that the kinship which occasions the experience of beauty may be felt only faintly, in the form of a trace [ichnos]. Thus, a second interesting feature of aesthetic experience is revealed in his description: the experience may be intense even though the connection to what occasions it is subtle and indirect. To some extent, this is true by definition, as the aesthetic concerns what is felt, rather than what is made obvious through reflective analysis. This is apparent in the aesthetics of art where subtlety and nuance are prized, and obviousness, when not intentionally ironic, is likely to be dismissed as kitsch. Moreover, as is often the case with someone not versed in the formal elements of design or composition, it need not be transparent to those who are moved by a work of art why they have been affected; we often know what we find aesthetically pleasing without knowing why (and, notoriously, often the artists themselves are unable to offer much guidance). Certainly the seriousness and depth of appreciation are enhanced as the principles of art become clear with education and reflection, but such understanding is not prerequisite for aesthetic experience. Indeed, much of the comprehension of art history and theory that constitutes art appreciation has little to do with aesthetics per se.

Yet, as we saw with his description of aesthetic kinship, Plotinus's insight here is especially fruitful when applied to the aesthetic appreciation of natural environments rather than artifacts. And, once again, the invitation to pursue this direction is offered by the naturalistic connotation Plotinus's language carries: íchnos, "trace," also refers to the spoor or track left behind by a wild animal, a fortuitous image for the discussion of environmental aesthetics. To follow that image, we may consider that the hunter or naturalist who enters a natural space may encounter an animal either directly or mediately through the traces the animal has left behind. In the latter case, the experience may be of something less photogenic, but it nonetheless imbues the space in which it is found with a significance - this is a habitat - and, relatedly, an aesthetic presence it would not otherwise have. In like manner, the sense of kinship between human and animal that I claim informs certain aesthetic encounters with nature need 
not be overt. Perhaps it is easily felt in the presence of our close mammalian relatives, but it also may be found in the face of cold-blooded amphibians; it is invited by picturesque views of charismatic megafauna, but the trigger can also be a rodent's gnaw-marks left on a piece of bone (...there are needs here...), an owl pellet (...life and death are around...), or the penetration of a sound or smell through a natural environment (...communication is taking place). While some who praise the aesthetic power of nature may do so as a result of a prior moral commitment to their kinship with other animals, more subtle and unexpected encounters with wild animals also may be the source for aesthetic appreciation of nature, as is attested to throughout a large body of environmental literature.

Those who resist welcoming other animals as kin may of course still describe their experience of nature as aesthetically charged, albeit in different terms. We might try to address their resistance with evidence of human/animal continuity gleaned from the modern biological sciences, with a view to prompting a reinterpretation of their aesthetic experience. Indeed, some (e.g. Carlson) have argued that scientific knowledge of the natural world is essential to the fully informed aesthetic appreciation of nature (just as, it may be argued, a knowledge of art history and theory is necessary for robust art appreciation). However, while an understanding of the environmental sciences may be sufficient to awaken in some a sense of kinship with the nonhuman world, it is problematic to see such knowledge as necessary for either aesthetic experience or recognition of our relatedness to the rest of nature. Consider, for example, any number of prescientific totemic cultures, in which recognition of kinship with elements of the natural world informed all fundamental social institutions, including their artwork and aesthetic sensibilities. Lacking the evidence available through modern genetics, these peoples nonetheless were able to perceive other animals as their kindred cohabitants of the world, something available to any sensitive observer today. Living close to nature, pre-agricultural societies integrated human/animal kinship in their worldview, in spite of their lack of modern scientific knowledge, because this relationship was infused throughout their lived experience. Consequently, whatever aesthetic experience preagricultural peoples had of nature and animals was no doubt very different from that available today to those in the developed world; indeed, one may question whether their appreciation of nature even qualifies as properly aesthetic. However, if we answer in the negative, it would not be because they lacked scientific knowledge of human/animal connections but rather because their awareness of these connections was so intertwined with their practical lives. ${ }^{8}$ Today, as the heirs of Western science - rich in knowledge of genetics and evolution, but often deprived of regular contact with what lies beyond our domesticated lives - any felt kinship with the natural world may

Humanimalia: a journal of human/animal interface studies

Volume 2, Number 2 (Spring 2011) 
be sparked unexpectedly, by subtle traces of ourselves we find in the animal's world. How typical such experiences are is an empirical question not easily answered. But when they do inform our aesthetic encounters with nature, they may offer us a more intense thrill than our forebears enjoyed.

The Aesthetic Startle. This point dovetails with a third feature of aesthetic experience expressed in Plotinus's description: the emotional state that accompanies the experience of beauty. Plotinus claims that the soul is thrilled [dieptôetai, from ptoeō, to scare, stun, excite; thus, startled might be a better rendering] by the encounter. Although the aesthetic is not reducible to a simple emotional reaction, it is also more affectively charged than the sober contemplation of beautiful forms. Plotinus explains this by claiming that the kinship which occasions the experience of beauty is found in an unexpected place; the soul finds a trace of its own spiritual nature present within the lower material world and is stunned at having found a relative in such a foreign land. Once more, the phenomenological reading of Plotinus's description may, in a metaphysically neutral way, be related to generally recognized features of art's aesthetic power. First, it might be said that an unexpected thrill is inherent to the aesthetic encounter with art. That such encounters often provoke verbal interjections - "That's beautiful!" or "Oh my!" or simply "Wow!" - is linguistic evidence that effective art does more than foster staid contemplation. The alchemy by which mere oil and wood can become a Madonna of Raphael and horsehair rubbing against catgut can produce a Bach violin concerto can be stunning to materialists and dualists alike, and offering such a startle is central to art's power. Second, an "aesthetic startle" fits with common explanations of how the artist is able to accomplish such transubstantiation. Although it is debatable whether successful artists are in possession of a unique "genius," few will deny that perceptual acuity and expressive depth allow them to reveal a novel side of common objects and experiences, to surprise the audience by revealing something that has in fact been near all along. Further, we might relate the experience of an aesthetic startle to the modern notion of disinterestedness: the subject may be struck by the power of a work of art - something that may be neither practically useful nor morally valuable - to evoke an intense sense of relatedness that is distinct from both the pleasant and the good, and serves no pragmatic interest.

Applied to nature aesthetics, Plotinus's description once again offers insights that are especially fruitful. If, following the preceding analysis, we accept that the aesthetic experience of the natural world is informed by the human observer's sense of at least a 
trace of kinship with this environment, would not a startle be an appropriate accompaniment for many who would discover this today? Finding kinship with something beyond human society would have been unavoidable for our early ancestors, but for us who have been detached from the natural world by centuries of industrialization, such experiences may often be unexpected and startling in the challenge they present to our human self-concept. Of course, North Americans are heirs of the culture that produced Henry David Thoreau and John Muir, and each tradition can cite its own historic icons of ecoconsciousness; thus it might be objected that the aesthetic power of nature should no longer surprise us today. But when our foodstuffs have spent more time in laboratories than in the elements, our healthcare system has reduced our bodies and minds to manipulable chemical systems, and our lives and labor have become increasingly mechanized - in sum, when most of our lived experience is that of technological hybrids rather than animals - the felt sense that we may bear any sort of kinship to living beings that thrive outside our cultural and industrial infrastructures will be disarming.

The notion of an aesthetic startle also speaks to the complexity of aesthetic experience. Compelling it may be, but even on Plotinus's pre-modern account, the beautiful is much more challenging than the pleasant recognition of symmetrical forms. The definition of art as the competent reproduction of pleasing images and sounds has been outgrown by the modern artworld; likewise, we should expect that today the aesthetic appreciation of nature must also be something more multifaceted and ambiguous. Perhaps the contemporary crisis in art and the renewed attention to environmental aesthetics are two faces of the same phenomenon, as we find ourselves awash in the civilized products of supercivilized human beings. These artifacts are not simply akin to us but are us, mirroring our state of utter domestication; with their power to produce an aesthetic thrill thus handicapped, contemporary artists are driven to pursue the outrageous and absurd. Environmental aesthetics takes on a new urgency in such a context, not only because of the practical threats that civilization poses to the survival of the nonhuman world, but also because the trace of kinship we find in the natural world, in the face of our animal relatives, reawakens the possibility of authentically startling aesthetic experience.

Naturalists and evolutionary psychologists speak of biophilia, an innate affinity between the human mind and the natural world from which it evolved, and we may find the term useful in connection with the kinship model of the aesthetic appreciation of nature. Yet, the term may also suggest an idealized interpretation of the kinship between humans and other animals, according to which the appreciation of nature must

Humanimalia: a journal of human/animal interface studies

Volume 2, Number 2 (Spring 2011) 
be an unambiguously positive reunion with our estranged animal relatives. On the contrary, "biophobia" may be a thoroughly authentic reaction for modern humans facing the uncivilized animal world; there, we may find much with which we are "out of tune" and "alienated," to use Plotinus's terms. Given the complex and varied relationships between human beings and the rest of the Earth's ecosphere, one would expect the fully honest aesthetic experience of nature to be capable of provoking both love and fear. Such variety is evident in the complex universe of human kinship: one can hunger to unite with a blood relative never before seen, while others spurn immediate family members with whom they have lived intimately for years. Likewise, those who turn to nature will - both at turns and perhaps simultaneously - be pleasantly surprised and horrified at the relatedness they feel to the world outside of civilization: I, too, am animal. The nature-goer may be delighted at a renewed appreciation of the breadth of human sentience, and a sense of attunement to a larger world not of human creation. Yet despite the fact that many naturalists have presented such experiences as positive and spiritually uplifting, these moments are not without tragic overtones, serving as stark and painful reminders of our amoral physicality and our utter mortality.

Aesthetic Recollection. Experienced in either of these ways, the aesthetic encounter with nature brings the observer into relation with something other, only to return with an altered understanding of herself and her place in the world. That aesthetic experience may culminate in such a moment of self-awareness is accounted for in Plotinus's description of the experience of beauty. He presents the aesthetic startle as a reawakening of sorts, for following it the observer's soul "returns to itself and remembers itself"; inherent to the thrill is that the aesthetic subject has a sense of rediscovering something of himself through his kinship with the aesthetic object. For Plotinus, this moment of recollection is caused by the subject beholding his own spiritual nature in the forms that take command of the beautiful material object. However, since kinship is a bidirectional relationship, the alternative interpretation - that the aesthetic observer finds something of the aesthetic source, something unexpected and baldly somatic, in him-or herself - is equally plausible, and especially significant in the case of nature aesthetics; indeed, to uncover something presumed to be alien within oneself would be the more startling, the more psychologically and aesthetically powerful experience. ${ }^{9}$ In any case, Plotinus's image of the kinship between observer and observed not only describes the experience of the aesthetic, but also allows for the sense that value and meaning may be 
generated from this experience. The aesthetic creates the possibility for emended selfunderstanding.

That such a possibility should exist has been the position of a powerful line of thinking in the philosophy of art. While some have held art to be mere amusement and stimulation, or, more ominously, a deleterious distraction from humankind's spiritual vocation, many others have stipulated that the aesthetic proper must in some way leave the appreciator enriched by the experience. This claim has been used as a tool for distinguishing between "high" and "low" art. While the products of popular culture no doubt have an aesthetic dimension to the extent that they operate on the registers of feeling, emotion, and sensation, they are often ill equipped to leave the consumer with much of enduring value; rather, they are likely to leave behind an absence, a hunger for further stimulation. In practice, distinctions between high and low, fine and popular art are problematic, and laden with political and class assumptions; what is at one time derided as mere "craft" or "popular art" may gain respect with political change or simply the remove of time. In theory, however, the demand that art has educational value and should promote the evolution of one's self-understanding seems a relevant criterion for categorizing, and perhaps evaluating, art.

With regard to the aesthetic appreciation of natural environments, whatever selfunderstanding may emerge from such experiences is inherently complicated. The actual observer of nature is never the ideal, and so whatever meaning is garnered from the aesthetic power of nature unavoidably will be filtered through the institutions and categories of culture. That there is the possibility of learning from the "pristine" reality of the natural world, uncontaminated by the detritus of human civilization, is a tantalizing prospect, one that naturalists from various perspectives have urged us to explore. But whether or not such hopes may be realized in practice is ultimately an epistemological problem that lies beyond the concerns of aesthetics proper. People may conclude that the kinship they feel to nature is evidence that there are traces of their most prized human attributes in the nonhuman world, or, conversely, that long derided elements of the natural world echo alarmingly within them. Which of those or the innumerable possibilities that lie between is ultimately settled upon will be determined by many factors. But that some conclusion must be considered in the light of these boundary-challenges, that one's self-concept is invariably informed by some -implicit or explicit - interpretation of our relationship with the natural world, may be a startling recollection to some. As we make daily strides toward achieving the Cartesian dream of becoming lords and masters of nature, and in the process insulate ourselves from daily contact with that dominion, it is easy to forget the common ancestry of the

Humanimalia: a journal of human/animal interface studies

Volume 2, Number 2 (Spring 2011) 
human and nonhuman worlds. In the information age, when so much of the content of our consciousness is produced by the machinery of technology and culture, it is easy to forget that value can be generated by other means.

The loss of death, the pain of disease and natural disasters can shatter that hubris. Traditionally, religion has been the venue where such experiences of suffering have coalesced into the conception of a reality not of our own making but which we must, with humility, be mindful of. The first Commandment instructs us to recognize the reality of God as something irreducible to the idols crafted by human hands. In the modern world, secular forms of thinking have supplanted this theological monopoly by drawing attention to the nonhuman reality closer to hand. Some philosophers have argued that our relatedness to animals and the environment - our common mortal vulnerability - establishes firm moral limits on what we may do to nonhumans; similarly, many scientists have argued that only by acknowledging our evolutionary history - our origins in the ecosphere we share with all life on earth - can we truly understand ourselves. Yet these arguments do not necessarily translate into the felt sense of kinship with nonhumans, and that sense may be prerequisite for taking the arguments and their humbling implications seriously. ${ }^{10}$ Today, the aesthetic appreciation of nature may provide the needed inspiration. In the being of a wild animal we encounter the face of nature, whose gaze beckons us to recollect our curious, uneasy kinship to the nonhuman world.

Conclusion. Plotinus's theory of material beauty plays an interesting role in the history of Western aesthetics: it served to reinforce the fundamental dualism of Platonic metaphysics, while influencing later aesthetic theories by suggesting a somewhat more positive role for aesthetic appreciation than classical Platonism had allowed. However, my reading of Plotinus's text - which leaves these metaphysical and historical considerations aside - reveals a description of aesthetic experience that is interesting and fruitful in unexpected ways. According to this description, the aesthetic is experienced as a thrilling awareness of a kinship between the subject and the object, one that has the power to refresh the subject's recollection of her own nature. As we have seen, such a description provides an interesting focal point around which many commonly recognized features of art appreciation and aesthetic theory may be connected. However, I have argued that it provides an especially fitting and useful account of at least certain forms of the aesthetic appreciation of natural environments. The natural world emerges today as a significant aesthetic object in art, popular culture 
and aesthetic theory just when our kinship with nature is strained by being pulled in conflicting directions: reinforced by a prevailing biological paradigm that emphasizes human continuity with the rest of life on earth, yet threatened by the obvious disruption our species has created on the planet. The kinship model accounts for why, in light of this tension, the natural world today will afford us aesthetic moments not appreciated in other contexts.

As this tension speaks to the crisis we face concerning how to inhabit the world, our encounters with animals - our cohabitants of the broader environment - will have a special place in creating these moments. In the presence of wild animals, we may feel a sense of relation to their world that is startling, one that entices us to recollect both the proximity and remoteness of that world to the domesticated civilization we normally inhabit. Whatever direction this recollection ultimately takes, whatever practical actions vis-à-vis nature it inspires, whatever modification to our self-concept it ultimately informs, the traces of kinship we find embodied in the being of other animals have an aesthetic power that can inform our experiences of the natural world today. The obvious beauty of majestic natural structures and scenes can overshadow these traces, but both the nature-goer and the aesthetic theorist will be rewarded for seeking them out and following where they lead.

\section{NOTES}

1) Carlson provides an authoritative analysis of the recent literature. Also valuable is Budd.

2) An influential example is Casey.

3) See my The Moral Menagerie: Philosophy and Animal Rights.

4) Enneads, 249-253 (Ennead I, tractate 6, chapter 6). The argument recalls Porphyry's description of his teacher as seeming "ashamed to be in the body."

\section{5) Cf. The Postmodern Animal.}

6) "To achieve a balanced understanding of the situation, we must keep in mind that, as with appreciation of art, serious appreciation of nature means appreciating it as what it in fact is; and yet at the same time we must recognize that this also means appreciating nature as what it is for us. This idea limits yet enriches what is involved in appropriate aesthetic appreciation." (Carlson 10)

Humanimalia: a journal of human/animal interface studies

Volume 2, Number 2 (Spring 2011) 
7) Carlson argues that the proper balance between subjectivity and objectivity is maintained by recognizing the importance of scientific understanding of nature for its aesthetic appreciation. I address this possibility in the subsequent.

8) Reflection on this point might shed some light on a longstanding problem in art history. The existence of Paleolithic cave paintings demonstrates that early humans had what appears to be genuine aesthetic sensibility, and that nonhuman animals existed as aesthetic objects in Paleolithic culture. But why were these works created in caves that were inhospitable and difficult to access, rather than for maximal exhibition? The standard explanation is that these works has ritualistic, shamanic functions, rather than the display function of later, "proper" art. However, another answer is suggested by the role of an aesthetic trace. These early humans lived thoroughly within the world of animals, and their kinship was apparent and obvious; thus, their aesthetic energies would need to be directed toward a different space in order to be fully satisfying. How thrilling it must have been for these early humans to discover that through their unique technical skill they could master the interiority of the cave, that in subtle and unexpected ways they could find kinship with whatever specters they encountered there. It is unlikely that nature qua nature was an aesthetic object for early humans, even though elements of nature pervade their powerful and spiritually charged artwork.

9) This offers another angle on the difference between the aesthetics of art and the aesthetics of nature, with the arrow of emphasis pointing in opposing directions: in art appreciation we find part of ourselves embodied in the material world; in nature appreciation we find something not of our own creation embodied in ourselves.

10) That this sense may be an essential component of aesthetics generally - and not unique to the aesthetic appreciation of nature - may be read into Kant 's famous claim (Critique of Judgment, §5) that "beauty only concerns men, i.e. animals, but still rational, beings - not merely qua rational...but qua animal also." The aesthetic presents itself as an intense and valuable experience that reminds us our full humanity - both that which grounds us in nature and that which transcends it.

\section{WORKS CITED}

Baker, Steve. The Postmodern Animal. London: Reaktion Books, 1999. 
Budd, Malcolm, The Aesthetic Appreciation of Nature: Essays on the Aesthetics of Nature. NY: Oxford UP, 2005.

Carlson, Allen. Aesthetics and the Environment: The Appreciation of Nature, Art and Architecture. London: Routledge, 2000.

Casey, Edward C. Getting Back into Place: Toward a Renewed Understanding of the PlaceWorld. Bloomington: Indiana UP, 1993.

Fellenz, Marc. The Moral Menagerie: Philosophy and Animal Rights. Urbana: U of Illinois P, 2007.

Midgley, Mary. Animals and Why They Matter. Athens, GA: U of Georgia P, 1983.

Plotinus, with an English Translation by A. H. Armstrong, vol. 1. Cambridge, MA: Harvard UP, 1966.

Humanimalia: a journal of human/animal interface studies

Volume 2, Number 2 (Spring 2011) 